\title{
Paranetiese deparabolisering van paroesie-gelykenisse by die Sinoptici en die Openbaring aan Johannes
}

J A du Rand

(RAU)

\section{ABSTRACT}

Paraenetic deparabolization of parousia parables in the Synoptics and the Revelation of John

The relevance of the contributions made by the early Christian prophets to the traditions of the Jesus-logia is at stake. When the author of Revelation probably uses Synoptic parable traditions in 2:7; 3:3 and 16:15, he literally transformed it by using the method of paraenetic deparabolization. This was done to apply his message to new receivers in a new situation.

\section{PROBLEEMSTELLING}

Die vraag is al dikwels geopper of die vroeë Christelike profete enige noemenswaardige bydrae gemaak het tot ons beter verstaan van die tradisies van die sogenaamde Jesus-woorde ${ }^{l}$. Indien dit aanvaar sou word dat Johannes, die outeur van die oorgelewerde geskrif Openbaring, 'n rondreisende apokaliptiese Christelike profeet was $^{2}$, is die verdere vraag of sy geskrif enige bewyse toon van sodanige oorgelewerde Jesus-woorde. Is Johannes se logia wat in Jesus se mond geplaas word, volgens Openbaring, deel van die Sinoptiese tradisie of moet dit as voor-Sinopties beskou word? Is dit direkte aanhalings of slegs verwysings? Onderstaande ondersoek is toegespits op logia in die raamwerk van die sogenaamde paroesie-gelykenisse indien dit met die bekende Sinoptiese gelykenisse in verband gebring word. Die doel is dan om an te toon dat Johannes die gelykenis-oorleweringe eiesoortig aanwend om funksioneel te wees in sy eie vertelling.

Ons vind in dié geval, by wyse van seleksie, sogenaamde logia in Openbaring wat spesifiek met Sinoptiese uitdrukkings in die Sinoptici in verband gebring kan word, te wete $2: 7 \mathrm{a}, 3: 3 \mathrm{~b}$ en 16:153. Die vraag is op watter wyse genoemde logia in Openbaring verband hou met die Sinoptiese tradisies. Sou dit kon wees dat sommige of moontlik al drie die logia direk met Jesus-logia verband hou? Het Johannes die verbandhoudende tradisies in reeds bekende vorme geken wat onafhanklik is van die Sinoptiese ge- 
skrewe evangelies? Dit word bevestigend alreeds getoon in Openbaring $3: 5 \mathrm{c}^{4}$, in die vorm van die volgende formule:

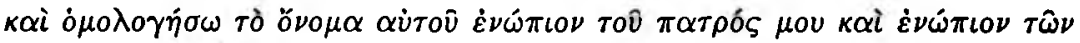
$\dot{\alpha} \gamma \gamma \varepsilon \lambda \omega \nu \alpha \dot{v} \tau o \hat{v}$ ("... en Ek sal voor my Vader en voor sy engele verklaar dat hy aan My behoort").

Dit verskil aansienlik van die soortgelyke uitdrukking in Lukas 12:8 (vgl Matt 10:32) waar $\tilde{\varepsilon} \mu \pi \rho \circ \sigma \theta \varepsilon \nu$ in plaas van $\dot{\varepsilon} \nu \omega \pi \iota \nu \nu$ gebruik word om juis die amptelike karakter van die belydenis te beklemtoon, soos om voor 'n regter 'n verklaring onder eed af te lê. Dit lyk of Openbaring eerder die klem op die paranetiese funksie laat valo. In die geval van die gekose drie, logia egter, sal die fokus veral val op Openbaring se afhanklikheid van die Sinoptiese tradisies, in watter vorm ook al. Die onderliggende paranetiese bedoeling van Openbaring, om naamlik die gemeentes te bemoedig en te berispe, moet deurgaans in gedagte gehou word.

\section{AANVANKLIKE VERKENNING VAN OPENBARING 2:7a; 3:3b EN 16:15}

Die eerste uitdrukking in 2:7a kom in al sewe die briefboodskappe voor en

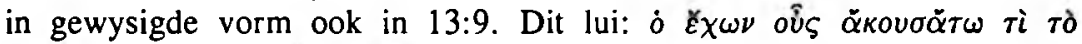
$\pi \nu \varepsilon \hat{v} \mu \alpha \lambda \hat{\varepsilon} \gamma \varepsilon \iota \tau \alpha \hat{\iota} \varsigma \dot{\varepsilon} \kappa \kappa \lambda \eta \sigma i \alpha \iota \varsigma$ ("Elkeen wat kan hoor, moet luister na wat die Gees vir die gemeentes sê"). Let veral op na Matteus 11:15; 13:9,43; Markus 4:9,23 en Lukas 8:8; 14:35 waar ồ $\varsigma$ vervang is deur $\hat{\dot{\omega}} \tau \alpha$. Die byvoeging van $\tau i$ тò $\pi \nu \varepsilon \hat{v} \mu \alpha \lambda \lambda_{\varepsilon \gamma \varepsilon \iota} \tau \alpha \hat{\imath} \varsigma \dot{\varepsilon} \kappa \kappa \lambda \eta \sigma i \alpha \iota \varsigma$ volgens Openbaring is betekenisvol. Dit roep die leser nie net op om aandag te skenk nie, maar beklemtoon ook onomwonde dat dit die woorde van die verhoogde Christus is wat deur die Heilige Gees tot sy gemeentes spreek. Die woorde van Jesus, soos weergegee deur die Sinoptici, verskil dus van dié van die Christelike apokaliptiese profeet Johannes s'n. Genoemde aankondigingsformule ${ }^{7}$ kan moontlik op twee wyses funksioneer: esoteries geïnterpreteer, is dit ' $n$ aanduiding daarvan dat wat gesê is, ' $n$ sogenaamde dieper of verborge betekenis het; paraneties geïnterpreteer, is dit 'n wekroep aan die luisteraars of lesers om ernstig ag te slaan op wat gesê is ${ }^{8}$. Wanneer die aankondigingsformule ' $n$ segging afsluit, funksioneer dit soos 'n profetiese handtekening om Goddelike sanksie te dra. Ou-Testamentiese profetiese orakels is dikwels ook afgesluit met 'n soortgelyke "Hoor die woord van die Here" (1 Kon 22:19; 1 Kron 18:18; Amos 7:16; Jer 29:20).

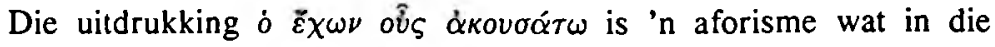
Jesus-tradisie gebed is en in ses variante voorkom op sewe plekke in die Sinoptiese tradisie, te wete Markus 4:9,23; Matteus 11:15; 13:9,43; Lukas 
8:8; $14: 359$. Dit is opmerklik dat dieselfde uitdrukking vyf keer in die Evangelie van Thomas voorkom as afsluiting van gelykenisse ${ }^{10}$.

Die volgende twee uitdrukkings word moeiliker aan die Sinoptiese tradisie verbind. Dit verg veel meer argumentasie om Sinoptiese koppelinge te vind met Openbaring 3:3b en 16:15.

In Openbaring 3:3b word Christus se "koms" metafories verduidelik deur die onverwagse koms van 'n dief met behulp van 'n voorwaarde-konstruksie:

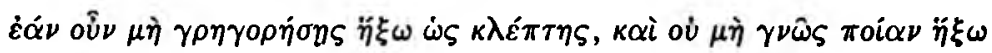
$\dot{\varepsilon} \pi i \sigma \varepsilon$ ("As julle nie wakker word nie, sal Ek onverwags kom soos 'n dief, en julle sal nie weet wanneer Ek op julle sal afkom nie").

Wanneer dié uitdrukking saamgelees word met 1 Tessalonisense 5:2 en 2 Petrus 3:10, voer dit die leser ongetwyfeld terug tot die tipiese voorstelling van Christus se skielike paroesie, wat soos 'n dief in die nag sal plaasvind. 1 Tessalonisense 5:2 stel dit só: "Julle weet self maar al te goed dat die dag van die Here onverwags kom soos 'n dief in die nag" ( $\dot{\omega} \varsigma \kappa \lambda \dot{\varepsilon} \pi \tau \eta \zeta \dot{\varepsilon} \nu$ $\nu v \kappa \tau i)$. En 2 Petrus 3:10 verwoord die waarskynlike gemeenskaplike oorlewering só: "Maar die dag van die Here sal so onverwags soos 'n dief kom" ( $\dot{\omega} \varsigma \kappa \lambda \varepsilon ́ \pi \tau \eta \varsigma)$.

Volgens die waarskynlike gemeenskaplike tradisie in dié twee gevalle, word die aanbreek van die "dag van die Here" vergelyk met die onverwagse koms van 'n inbreker. En in Openbaring 3:3b word Christus se skielike koms om te oordeel daarmee vergelyk. Al die gegewens sover in ag geneem, laat ons terugblaai na die Q-weergawe van die gelykenis van die wakende huiseienaar (vgl Matt 24:42-44 en Luk 12:39-40) waar dieselfde onderliggende tradisie voorkom. Die waaksaamheid van die huiseienaar word aangewend om die lesers op te roep om te waak met die oog op die onverwagse koms van die Seun van die mens.

Die onverwagse aanbreek van die dag van die Here het mettertyd in die gang van die tradisie oorgegaan in die onverwagse koms van die Seun van die mens'1. Dit is ook dié ontwikkeling wat neerslag gevind het in die paranetiese interpretasie van die tradisie volgens Openbaring 3:3b. Dieselfde geld die verstaan van Openbaring 16:15: “Kyk, Ek kom onverwags soos 'n dief. Geseënd is die een wat wakker bly en sy klere reghou, sodat

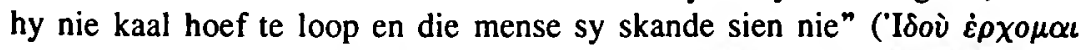

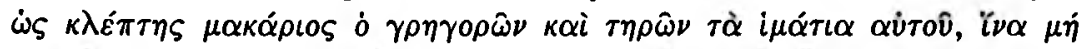

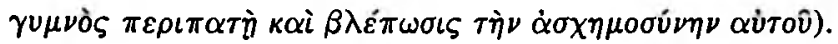

In al drie gevalle word die navorser teruggevoer tot 'n aanname wat dui op 'n gemeenskaplike tradisie rakende waaksaamheid. 'n Nadere ondersoek na die Sinoptiese gelykenisse waarin dié tradisie vervat is, is daarom noodsaaklik. 
Die gelykenisse oor die waaksame slawe en die dief is volgens die Lukaanse weergawe (12:35-40) deel van 'n groep paroesie-gelykenisse wat konsentreer op die onverwagsheid van die aanbreek van die paroesie. Een van die aspekte van die onverwagsheid is dat niemand weet wanneer die Seun van die mens sal kom nie; daarom die paranetiese oproep om altyd

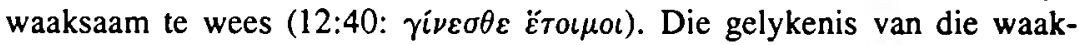
same slawe volgens Lukas 12 fokus op die paroesie as 'n seën vir diegene wat waaksaam is, terwyl dié oor die dief fokus op die paroesie as oordeel vir die onvoorbereides. Die elemente van seën én oordeel speel dus 'n belangrike rol ${ }^{12}$. Die toepassing van albei gelykenisse volgens Lukas is op gereedheid en in waaksaamheid. Die verwysing na die dief word ook nie in 'n nagkonteks geteken nie. Om die koms van die Seun van die mens met die onverwagse inbraak van 'n dief te vergelyk, en dan op Christus toe te pas, kom tog vreemd voor. Ter wille van paranetiese doeleindes word die oorspronklike tradisie literêr omvorm.

Volgens ' $n$ vergelyking met die Matteusweergawe (24:43-44) moet 'n mens aflei dat Lukas se vertelling byna woordeliks ooreenkom met dié van $Q$. Matteus voeg net die nagraamwerk by, vervang Lukas se $\ddot{\omega} \rho q$ met $\phi v \lambda \alpha \kappa \hat{\eta}$ en voeg $\dot{\varepsilon} \gamma \rho \eta \gamma o ́ \rho \eta \sigma \varepsilon \nu$ by. Diewe is oor die algemeen met die nag geassosieer in die antieke wêreld. Matteus het dié Lukaanse gelykenis van wakende slawe (Luk 12:35-38) en die Markaanse gelykenis van die deurwagter wat waaksaam moet bly (Mark 13:33-37), weggelaat. Deur assosiasie is sowel die temas van waaksaamheid as die onverwagse koms van die dag van die Here en die Seun van die mens voortgedra in die tradisie met die hulp van die paroesie-gelykenisse. Die toepassing in die paroesiegelykenisse het mettertyd ontwikkel en gewissel na gelang van die konteks en omstandighede van die lesers. En dit bring ons by die verskynsel van deparabolisering.

Deparabolisering vind plaas wanneer die toepassing van die gelykenis sodanig gedoen word dat dit die literêre struktuur van die gelykenis afbreek of wysig. Die tipiese narratiewe elemente van die gelykenis word in die nuwe toepassing vervang deur metaforiese stellings of opdragte wat meestal paraneties van aard is - in ooreenstemming met die situasie van die lesers of luisteraars. Lukas se gelykenis van die wakende slawe begin byvoorbeeld reeds met 'n paranetiese oproep in 12:35: "Wees gereed, die

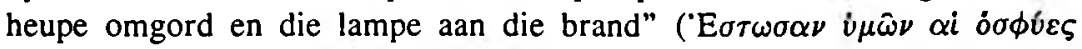

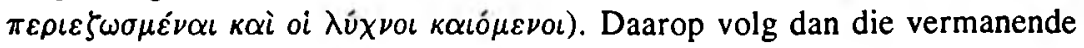
narratief in vers 36 , dat die slawe moet wees soos mense wat op hul 
eienaar wag sodat hulle dadelik vir hom kan oopmaak as hy van die bruilof

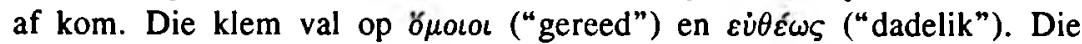
daaropvolgende twee seënspreuke funksioneer reeds as toepassing in verse 37 en 38. Die lesers moet ook waaksaam wees, net soos die slawe wat te enige tyd wakker is om oop te maak vir hul eienaar wat enige tyd kan opdaag.

Volgens deparabolisering in Markus 13:33-37, wat as parallel funksioneer met Matteus 24:36-44, word die deurwagter wat waaksaam moet bly, volgens die toepassing gelyk gestel aan die lesers. Uiteindelik het daar in Markus 13:33-36 net vers 34 oorgebly van die oorspronklike gelykenisnarratief, terwyl verse 35-36 'n direkte aanspreek van die lesers beskryf in die vorm van toepassing. Die lesers het reeds deur literêre deparabolisering die "deurwagters" "geword". 'n Oorspronklike gelykenis is literêr omvorm om aan te pas by die situasie van die lesers of luisteraars.

Van 'n moontlike oorspronklike gelykenis het daar in 1 Tessalonisense 5:2 en 2 Petrus 3:10 slegs die toepassende vergelykende $\dot{\omega} \varsigma \kappa \lambda \varepsilon ́ \pi \tau \eta \varsigma$

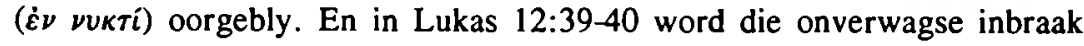
deur 'n dief toegepas op die skielike koms van die Seun van die mens. Deur deparabolisering is die gelykenis, by wyse van spreke, literêr verwring deur die toepassing.

Verskeie merkwaardige ooreenkomste tussen Didage 16:1 en die Sinoptiese weergawes oor die dief wat inbreek, onderstreep die feit dat die paroesie-gelykenismateriaal in algemene gebruik in die vroeë kerk was. Vergelyk byvoorbeeld die volgende uitdrukkings:

$\gamma \omega \eta \gamma о \rho \varepsilon \hat{\tau} \tau \varepsilon$ i $\pi \varepsilon \rho \tau \hat{\eta} \varsigma \zeta \omega \hat{\eta} \varsigma \dot{v} \mu \hat{\omega} \nu$ met Matteus 24:42;

oi $\lambda \dot{v} \chi \nu \circ \iota \dot{v} \mu \hat{\omega} \nu \mu \grave{\eta} \sigma \beta \varepsilon \sigma \theta \dot{\eta} \tau \omega \sigma \alpha \nu$ met Lukas 12:35;

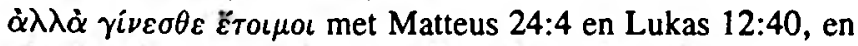

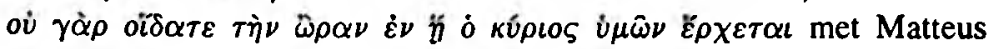
24:42 en Lukas 12:46.

Didage 16 is 'n uitstekende voorbeeld van eskatologiese-paranetiese toepassing van paroesie-gelykenisse, wat literêr nuut aangewend is. Die gelykenisse van die waaksame slawe en dief het in latere weergawes as gevolg van deparabolisering bloot net vergelykings of metaforiese vermanings geword wat losstaande van die oorspronklike gelykenis gebruik kon word in die gemeentesituasie. Dit het egter nie beteken dat die gelykenisse as sodanig nie gewilde narratiewe gebly het nie ${ }^{13 !}$ Juis deur literêre omvorming, is die gelykenis steeds bly gebruik om die temas waaksaamheid en eskatologiese gereedheid voort en voor te dra in die vroeë Christelike kerk. In só 'n raamwerk van moontlike tradisie-oorlewering moet die verwysings van paroesie-gelykenisse in Openbaring 3:3b en 16:15 verstaan word. 
Die gekose logia in Openbaring 3:3b en 16:25 hou verband met paroesiegelykenisse soos oorgelewer in die tradisies van die kerk. Die inhoud van Openbaring 3:3b stem byvoorbeeld ooreen met die Q-weergawe van die gelykenis oor die dief, maar voeg elemente by, net soos Matteus. Die vergelykende $\dot{\omega} \varsigma \lambda \lambda \dot{\varepsilon} \pi \tau \eta \zeta$ is reeds 'n vorm van deparabolisering, versterk deur die klem op die Ek-inkleding. Die primêre fokus van die gelykenis konsentreer op 'n oordeelselement in die paroesie, terwyl die Ek-toepassing die skielike koms van Christus beklemtoon. Volgens Openbaring 16:15 het die toepassing die fokus verskuif na dié persoon wat wakker bly en gereed is deur middel van 'n seënspreuk: Gelukkig is die man wat wakker bly met sy klere aan teenoor die man wat naak betrap word wanneer hy skielik gedurende die nag wakker gemaak word. Hierdie beeldspraak oor waaksaamheid volgens Openbaring 16:15 moet egter nie met dié oor die skielike koms van die dief in die nag verwar word nie. By die gelykenis van die dief handel dit oor die skielike en onverwagte aard van die koms van die paroesie, terwyl die gevaar dat die gelowige onverhoeds betrap kan word, aanleiding gegee het tot die metafoor om wakker te bly. Die seënspreuk het in Openbaring 16:15 'n nuwe element bygevoeg! Dit is om nie net wakker te bly nie, maar om ook te alle tye gereed te wees.

Deur deparabolisering het die gelykenis nuwe seggingskrag gekry in 'n nuwe situasie. Die seënspreuk is moontlik 'n uitbreiding op wat in Lukas 12:37-38 gedoen is: "Gelukkig is die slawe wat hy wakker aantref, selfs al sou hy eers om middernag of met hanekraai kom". Die eksegetiese probleem fokus op die uitdrukking $\tau \eta \rho \hat{\omega} \nu \tau \grave{\alpha} i \mu \alpha \dot{\tau} \tau \alpha$ in Openbaring 16:15. Sou dit kon beteken dat die waaksame sy klere moet aanhou of byderhand moet hou ${ }^{14}$ ? Die seënspreuk in Openbaring 16:15 is in elk geval 'n kreatiewe ontwikkeling op die Sinoptiese tradisie. Jesus kom $\dot{\omega} \varsigma \kappa \lambda \varepsilon \dot{\pi} \tau \eta \varsigma$ (soos 'n dief) volgens Openbaring 16:15 en $\dot{\omega} \varsigma \alpha \lambda \varepsilon ́ \pi \tau \eta \varsigma$ (soos 'n dief) volgens Openbaring 3:3b.

Die motief om waaksaam te bly gedurende die nag het 'n plekkie verower in die toepassing van die gelykenis van die dief. Eers was die klem net op die onverwagsheid daarvan, maar deur kreatiewe literêre ontwikkeling is waaksaamheid bygevoeg (Matt 24:43; 1 Tess 5:4-7; Op $3: 3 ; 16: 15$ ).

Sowel in 1 Tessalonisense 5:4-7 as in Openbaring 16:15 is die gelykenis van die dief die inhoudelike vertrekpunt wat dan lei tot uitbreidings na gelang van die situasie van die lesers. Die uitbreidings bevat deparabolisering sodat die literêre eindformaat weinig integrale relasie toon met die 
oorspronklike gelykenis. Die simboliek van klere en naaktheid is bygevoeg in die geval van Openbaring 16:15 na aanleiding van die tema waaksaamheid.

Die proses van literêre deparabolisering na aanleiding van die paranetiese behoeftes van die vroeë kerk het ongetwyfeld die tradisieproses van die paroesie-gelykenisse beïnloed. Die nuwe Sitz im Leben van die gemeentesituasie het paranetiese materiaal vereis. Ten einde dit gesaghebbend aan te bied, is ryklik gebruik gemaak van die Jesus-woorde; soos vervat in die paroesie-gelykenisse. Aan die een kant het die paranese die paroesie-gelykenisse en daarom ook die oorgelewerde Jesus-woorde lewend gehou en aan die ander kant het die gelykenisse terselfdertyd gedien as gesaghebbende narratiewe basis om die paranetiese boodskap oor te dra. Dit moes noodwendig invloed uitgeoefen het op die Sinoptiese tradisie ten opsigte van die formele formaat en oordrag van tradisies ${ }^{15}$. En in dié opsig het die Christelike profete waaronder Johannes wat as outeur van Openbaring bekend staan, kreatief deelgeneem aan die oorlewering van die Jesuswoorde.

Dit het nie noodwendig beteken dat Johannes vertroud was met reeds geskrewe tekste van die kanonieke Evangelies nie. Só 'n moontlikheid kan ook nooit net van die tafel gevee word nie. Dit staan vas dat die Jesuswoorde lewend oorgelewer is in die vroeë kerk en daarom ook 'n regmatige plek in die liturgie van die vroeë kerk sou inneem ${ }^{16}$. Die gesaghebbendheid waarmee die Jesus-woorde volgens die paroesie-gelykenisse deur Johannes bejeën en aangewend is, wek tog die indruk dat die Sinoptiese tradisie in een of ander gesaghebbende formaat (geskrewe of mondelings) beskikbaar kon wees, of ten minste só bekend was dat Johannes hom in sy paraenese daarop kon beroep het.

\section{NOTAS:}

1 Vergelyk verder J D G Dunn, Prophetic "I"-sayings and the Jesus Tradition: The Importance of Testing Prophetic Utterances within early Christianity, NTS 24 (1978), 175-198; asook D E Aune, Prophecy in Early Christianity and the Ancient Mediterranean World, Grand Rapids 1983, 233-245.

2 Kyk J A du Rand, Johannese Perspektiewe: Inleiding tot die Johannese geskrifte, Midrand 1991, 187-192.

3 Ander moontlike logia wat verband hou met die Ou Testament, is onder andere $1: 7 ; 3: 19 \mathrm{a} ; 22: 12,13$. Vergelyk in dié verband $\mathrm{R}$ Bauckham, The Climax of Prophecy. Studies on the Book of Revelation, Edinburgh 1993, 93-94; asook L A Vos, Synoptic Traditions in the Apocalypse, Kampen 1965, 220-227.

$4 \quad$ Vergelyk Matteus 10:32 en Lukas 12:8, asook Markus 8:38.

$5 \quad$ Kyk I H Marshall, The Gospel of Luke, Exeter 1978, 515. In die uitdrukking o

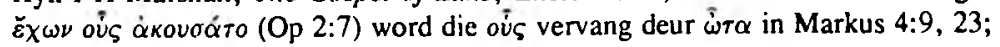


Matteus $11: 15 ; 13: 9,43$; Lukas $8: 8 ; 14: 35$. Vergelyk ook die Evangelie van Thomas $8,21,24,63,65,96$.

6 Verdere moontlike verwysings in Openbaring na die Sinoptiese tradisie is Openbaring 3:5c (vgl Matt 10:32, Op 1:3 (vgl Luk 11:28); Openbaring 1:7 (vgl Matt 24:30); Openbaring 11:2 (Luk 21:24); Openbaring 13:10 (Matt 26:52); Openbaring 19:9 (Matt 22:1-14). Kyk verder R H Charles, The Revelation of St John, Edinburgh 1920, Volume 1, Ixxxiv-Ixxxvi. Charles meen dat Johannes vertroud was met die Evangelies volgens Matteus en Lukas.

7 In Duits weergegee deur Weckruf of Weckformel.

8 Vergelyk D E Aune, Revelation 1-5, Word Biblical Commentary, Volume 52, Dallas, Texas 1997, 150.

$9 \quad$ Kyk Aune, $a w, 1993,150$.

10 Vergelyk Evangelie van Thomas 8,21,24,63,65,96.

11 ' $n$ Klinkklare bewys hiervan is onder andere die nie-Christologiese interpretasie van 'n soortgelyke tradisie in die Evangelie van Thomas, 21 . Vergelyk verder $A$ Y Collins, The Son of Man Tradition and the Book of Revelation, in: $\mathbf{J ~ H}$ Charlesworth, The Messiah. Developments in Earliest Judaism and Chirstianity, Minneapolis 1992, 536-568.

12 Vergelyk Marshall, $a w, 533$.

13 Aldus Bauckham, $a w, 1993,104$.

$14 \quad \mathrm{Na}$ aanleiding van Amos 2:16 sou 'n mens aan die beeld van 'n soldaat kon dink wat op 'n gereedheidsgrondslag moet gaan slaap, gereed vir enige gebeurlikheid of selfs 'n veldslag wat voorlê.

15 Bauckham, $a w, 112-117$, vermeld ook die volgende moontlike noemenswaardige buite-bybelse verwysings na die paroesie-gelykenisse: Hemelvaart van Jesaja 4:16; Sibillynse Orakel 2:177-183; Methodius, Symposium 5:2; Epifanius, Haereses 69:44:1 en in die Etiopiese en Koptiese weergawes van die Brief van die Apostels 43:1-2.

16 Vergelyk Aune, aw, 1997, 265; asook L A Vos, a w, 224. 